\title{
Developmental regulation of expression of schizophrenia susceptibility genes in the primate hippocampal formation
}

\author{
G Favre ${ }^{1}, \mathrm{P}$ Banta Lavenex ${ }^{1,2}$ and P Lavenex ${ }^{1,2}$
}

The hippocampal formation is essential for normal memory function and is implicated in many neurodevelopmental, neurodegenerative and neuropsychiatric disorders. In particular, abnormalities in hippocampal structure and function have been identified in schizophrenic subjects. Schizophrenia has a strong polygenic component, but the role of numerous susceptibility genes in normal brain development and function has yet to be investigated. Here we described the expression of schizophrenia susceptibility genes in distinct regions of the monkey hippocampal formation during early postnatal development. We found that, as compared with other genes, schizophrenia susceptibility genes exhibit a differential regulation of expression in the dentate gyrus, CA3 and CA1, over the course of postnatal development. A number of these genes involved in synaptic transmission and dendritic morphology exhibit a developmental decrease of expression in CA3. Abnormal CA3 synaptic organization observed in schizophrenics might be related to some specific symptoms, such as loosening of association. Interestingly, changes in gene expression in CA3 might occur at a time possibly corresponding to the late appearance of the first clinical symptoms. We also found earlier changes in expression of schizophrenia susceptibility genes in CA1, which might be linked to prodromal psychotic symptoms. A number of schizophrenia susceptibility genes including APOE, BDNF, MTHFR and $S L C 6 A 4$ are involved in other disorders, and thus likely contribute to nonspecific changes in hippocampal structure and function that must be combined with the dysregulation of other genes in order to lead to schizophrenia pathogenesis.

Translational Psychiatry (2012) 2, e173; doi:10.1038/tp.2012.105; published online 23 October 2012

\section{Introduction}

The hippocampal formation is implicated in a number of neurodevelopmental, neuropsychiatric and neurodegenerative disorders including schizophrenia, ${ }^{1}$ autism spectrum disorders, ${ }^{2}$ temporal lobe epilepsy, ${ }^{3}$ Down syndrome, ${ }^{4}$ Williams syndrome, ${ }^{5}$ antisocial personality disorder and psychopathy, ${ }^{6}$ bipolar disorders, ${ }^{7}$ major depressive disorder ${ }^{8}$ and Alzheimer's disease. ${ }^{9}$ Although these pathologies are all associated with abnormalities in hippocampal structure or function, they exhibit specific characteristics, such as individual groups of susceptibility genes and the fact that distinct regions of the hippocampal formation are differentially affected in specific pathologies. ${ }^{10}$

The hypothesis that schizophrenia emerges from the interaction between genetic predispositions and environmental factors is now widely accepted. ${ }^{11}$ The genetic component of schizophrenia was first suspected since relatives of subjects with schizophrenia are more likely to get the illness themselves. ${ }^{12}$ Indeed, the risk of suffering from schizophrenia in the general population is about $1 \%$; people who have a third-degree relative (great grandparent, first cousin) with schizophrenia are twice as likely to develop schizophrenia (2\%); those with a second-degree relative (grandparent, uncle, aunt) have an incidence varying from 2 to $6 \%$; finally first-degree relatives (parent, sibling) have an incidence of schizophrenia $>10$ times higher than the general population ( $13 \%$ for children, $17 \%$ for twins and $48 \%$ for identical twins). ${ }^{13}$ Accordingly, linkage analysis, gene expression and genomewide association studies have identified a number of schizophrenia susceptibility genes. ${ }^{14,15}$

The fact that schizophrenia more often appears in late adolescence and early adulthood suggests that schizophrenia is a disorder of developmental origin. Moreover, prodromal symptoms like affective disorders, substance abuse, personality disorder, autism spectrum disorder-like symptoms, developmental delays, delusions or hallucinations can be found in patients years before they finally develop schizophrenia. ${ }^{16}$ This suggests that the dysregulation of expression of schizophrenia susceptibility genes might affect normal brain development, leading to the gradual appearance of different symptoms at different ages.

Magnetic resonance imaging studies consistently report reduced hippocampal volumes in first-episode schizophrenic subjects ${ }^{17}$ and asymptomatic, first-degree relatives of subjects with schizophrenia, ${ }^{18}$ indicating that hippocampal pathology is not the result of the illness or treatment but rather contributes to the etiology of the disorder. The absence of obvious signs of neurodegeneration confirms the idea that schizophrenia is a neurodevelopmental disorder, ${ }^{19}$ which might arise following the abnormal maturation of specific hippocampal circuits. ${ }^{20,21}$

\footnotetext{
${ }^{1}$ Department of Medicine, Laboratory of Brain and Cognitive Development, University of Fribourg, Fribourg, Switzerland and ${ }^{2}$ Laboratory for Experimental Research on Behavior, Institute of Psychology, University of Lausanne, Lausanne, Switzerland

Correspondence: Professor P Lavenex, Institute of Psychology University of Lausanne, Quartier UNIL - Dorigny, CH-1015, Lausanne, Switzerland.

E-mail: pierre.lavenex@unil.ch

Keywords: Alzheimer; autism spectrum disorder; epilepsy; hippocampus; schizophrenia; Williams

Received 6 July 2012; revised 28 August 2012; accepted 31 August 2012
} 
Here we analyzed the expression of 173 schizophrenia susceptibility genes in distinct regions of the monkey hippocampal formation during early postnatal development, in order to assess the contribution of these genes to the normal development of the hippocampal formation and shed light on the pathogenesis of schizophrenia. We further considered schizophrenia susceptibility genes involved in other diseases, including temporal lobe epilepsy, autism spectrum disorder, Williams syndrome, psychopathy, major depressive disorder, bipolar disorder and Alzheimer's disease, in order to better comprehend the possible relations between gene dysregulation, neuropathology and clinical symptoms.

\section{Materials and methods}

RNA samples. Sixteen male rhesus monkeys (Macaca mulatta; four 1-day-old, four 6-month-old, four 1-year-old and four 6-12-year-old) were used for this study. These animals were the same used in previous studies. ${ }^{22,23} \mathrm{We}$ refer the reader to these publications for detailed descriptions of RNA sample acquisition and microarray analyses using the GeneChip Human Genome U133 Plus 2.0 (Affymetrix, Santa Clara, CA, USA).

Data analysis. Analyses of gene expression levels were performed with Genespring GX 11 (Agilent Technologies, Santa Clara, CA, USA) and a custom-made script for repeated-measures analysis of variance. Probe-level analysis was performed with the Robust Multichip Averaging algorithm. Data were log2 transformed and an analysis of variance was performed in order to identify genes with differential expression in distinct hippocampal regions at different ages. Adjusted $P$-values for multiple comparisons were calculated with the false discovery rate method of Benjamini and Hochberg. ${ }^{24}$ We found 15392 probesets exhibiting significantly different expression between ages (corrected $P$-values $<0.05)$; 33147 probesets exhibiting significantly different expression between regions (corrected $P$-values $<0.05$ ); and 9511 probesets exhibiting a differential expression between ages and regions (interaction age $\times$ region; corrected $P$ values $<0.05)$. Only genes represented in one of these three groups of probesets were considered for the follow-up analyses (17002 genes). We performed statistical analyses comparing gene expression between newborns and adults within distinct hippocampal regions (that is, entorhinal cortex, dentate gyrus, CA3, CA1, subiculum) using two-tailed unpaired $t$-tests (significance level was set at $P<0.05$ ).

Gene expression patterns. The specific genes exhibiting either a significant increase or decrease in expression in any of the five hippocampal regions, among the 173 schizophrenia susceptibility genes ${ }^{15}$ and among all human proteincoding genes (20741) present in our microarray data, are listed in Supplementary Information 1 and 2. When one gene was represented by more than one probeset, we only considered the probeset exhibiting the largest change. As described in a previous study, ${ }^{23}$ some genes may be represented by different probesets exhibiting opposite patterns of expression; with an upregulated pattern that might represent the expression of microRNA targeting that gene, rather than mRNA. We therefore eliminated the probeset susceptible to represent microRNA expression. Finally, for genes that were identified as particularly important for the functional analyses, we examined the characteristics and specificity of the probesets, and nonspecific probesets were eliminated. Supplementary Information 3 presents the gene expression patterns of the probesets representing the 173 schizophrenia susceptibility genes considered here.

Functional analyses. We used the Database for Annotation, Visualization and Integrated Discovery (DAVID) functional annotation tool ${ }^{25}$ to perform functional analyses of particular gene groups. DAVID provides the number of genes for each enriched functional term in a given list of genes, the percentage of total genes involved, and calculates a modified Fisher's exact $P$-value comparing the number of genes included in a functional category and the number of genes present in a control list (genes randomly chosen in the Affymetrix H133 Plus 2.0 by DAVID, Affymetrix, Santa Clara, CA, USA).

\section{Results}

\section{Gene expression patterns}

Schizophrenia. We found that a greater proportion of schizophrenia susceptibility genes, as compared with all human protein-coding genes, exhibited a downregulation of their expression from birth to adulthood in distinct hippocampal regions: dentate gyrus (ratio schizophrenia genes/all genes: 1.82; chi-square(1): 13.361, $P<0.001$ ), CA3 (ratio: 1.40; chisquare(1): $7.783, P<0.01$ ) and CA1 (ratio: 1.47; chisquare(1): 13.406, $P<0.001$; Figure 1 and Supplementary Information 2). In contrast, a smaller proportion of schizophrenia susceptibility genes, as compared with all genes, exhibited an upregulation of their expression from birth to adulthood in CA3 (ratio: 0.63; chi-square(1): 4.138, $P<0.05$ ) and CA1 (ratio: 0.42 ; chi-square(1): $9.150, P<0.005$ ). These findings suggest that schizophrenia susceptibility genes are particularly involved in the postnatal development of the hippocampal formation, and point to the dentate gyrus, CA3 and $\mathrm{CA} 1$, as crucial regions in the pathogenesis of schizophrenia. Consequently, we analyzed in more detail the expression patterns of these genes in these three regions.

Dentate gyrus. Among the 33 schizophrenia susceptibility genes that exhibited lower expression levels in adult than newborn monkeys, 13 (39\%) exhibited a higher expression level at birth than at any other age, 8 (24\%) exhibited a lower expression in adulthood than at any other age, and $4(12 \%)$ exhibited a higher expression in newborn and 6-month-old monkeys, as compared with 1-year-old and adult monkeys (Figure 2a, Supplementary Information 1 and 3).

CA3. Among the 54 schizophrenia susceptibility genes that exhibited lower expression levels in adult than newborn monkeys, 34 (63\%) exhibited a lower expression level in adults as compared with any other age (Figure 2b, Supplementary Information 1 and 3).

CA1. Among the 67 schizophrenia susceptibility genes that exhibited lower expression levels in adult than newborn monkeys, 35 (52\%) genes exhibited a higher expression level 
a

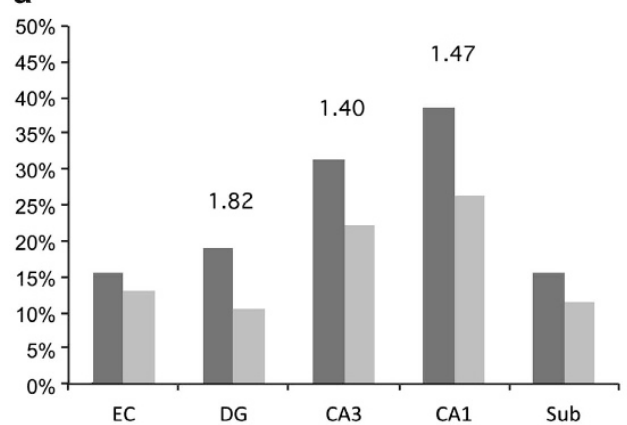

b

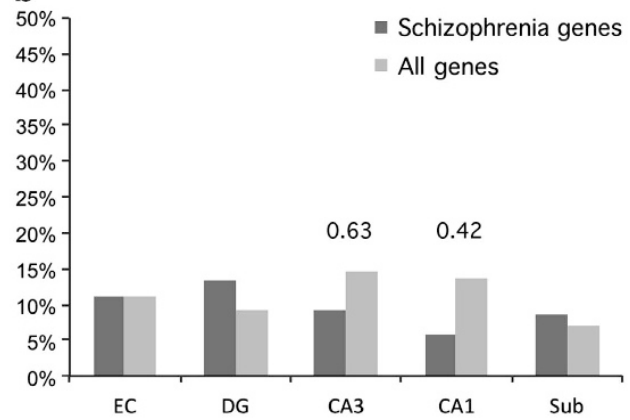

Figure 1 Percentages of schizophrenia susceptibility genes regulated in distinct hippocampal regions from birth to adulthood. (a) Decreased expression. (b) Increased expression. Schizophrenia susceptibility genes (173; dark gray); protein-coding human genes (20 741; light gray). DG, dentate gyrus; EC, entorhinal cortex; Sub, subiculum.
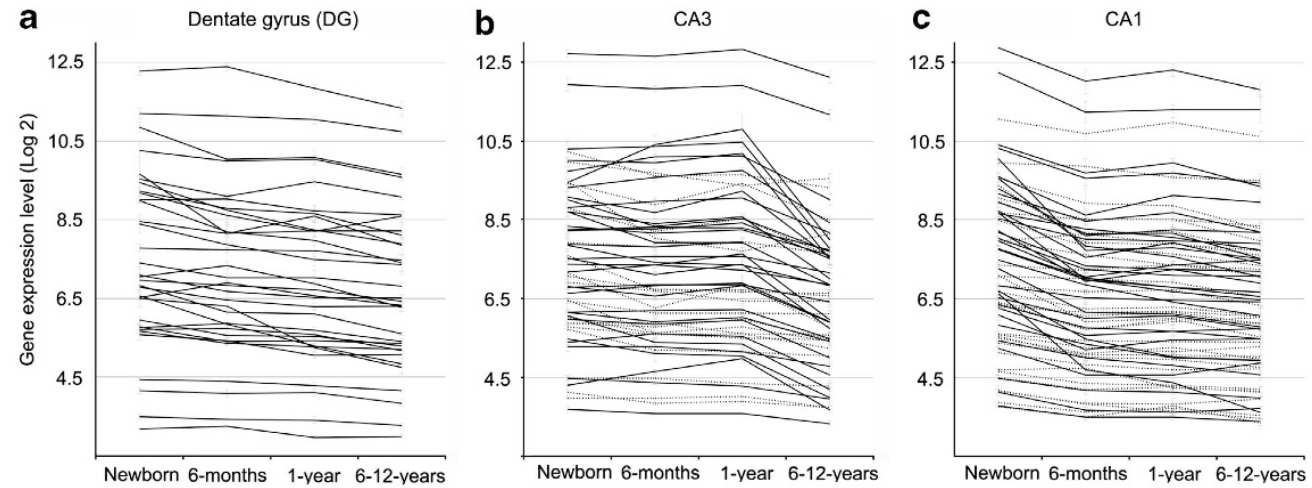

Figure 2 Expression patterns of schizophrenia susceptibility genes regulated in the dentate gyrus, CA3 and CA1 from birth to adulthood. (a) Dentate gyrus. (b) CA3: 34 schizophrenia susceptibility genes (63\%, solid lines) exhibit a significantly lower expression in adults than at any other ages. (c) CA1: 35 schizophrenia susceptibility genes (52\%, solid lines) are significantly more expressed at birth than at any other ages. Error bars represent s.e.

in newborn monkeys as compared with any other age (Figure 2c, Supplementary Information 1 and 3).

In sum, the gene expression patterns observed in CA3 and CA1 suggest that schizophrenia susceptibility genes might impact the normal maturation of these two distinct hippocampal regions at different postnatal stages.

Multiple pathologies. We further considered schizophrenia susceptibility genes implicated in other disorders in order to comprehend the possible relations between gene dysregulation, neuropathology and clinical symptoms. In all, 28 of the 173 schizophrenia susceptibility genes (16\%) are also implicated in other neuropsychiatric disorders that exhibit neuroanatomical or functional abnormalities in the hippocampal formation (Table 1). Among these genes, 10 are implicated in temporal lobe epilepsy, ${ }^{26,27} 8$ in psychopathyantisocial personality disorder, ${ }^{28-30} 7$ in autism spectrum disorder, ${ }^{31-34} 7$ in major depressive disorder, ${ }^{35-38} 6$ in bipolar disorder, ${ }^{39-44} 2$ in Alzheimer's disease ${ }^{45,46}$ and 1 in Williams syndrome. ${ }^{47}$ There was no overlap between groups of genes implicated in schizophrenia and Down syndrome. ${ }^{48}$ As compared with all genes exhibiting a change in expression from birth to adulthood, we found a greater proportion of multiple pathology susceptibility genes exhibiting a downregulation of their expression from birth to adulthood in the dentate gyrus (ratio: 3.06; chi-square(1): 13.913, $P<0.001$ ), CA3 (ratio: 1.76; chi-square(1): 4.629, $P<0.05$ ) and CA1 (ratio: 1.62; chi-square(1): 3.899, $P<0.05$; Figure 3 and Supplementary Information 4). We did not find differences among genes exhibiting an upregulation of their expression from birth to adulthood in any region.

\section{Functional analyses}

Schizophrenia. In order to characterize the cellular processes that might be affected in schizophrenia, we sought to determine the specific genes and functional processes regulated in the dentate gyrus, CA3 and CA1 (Table 2). In the dentate gyrus, schizophrenia susceptibility genes that were regulated during postnatal development were linked to neurogenesis, neuron and glial differentiation, axogenesis as well as to cell adhesion molecules. In CA3, schizophrenia susceptibility genes that were regulated were linked to dendritic morphology, synaptic plasticity, synaptic transmission and neuron projection. These findings are consistent with changes in neurotransmitter markers and synaptic morphology in CA3 in schizophrenia. ${ }^{49,50}$ One functional group comprises the GluN2B glutamatergic receptor subunit, which might be linked to 'associative learning' impairments observed in schizophrenics. The functional group 'calcium pathway' was only identified in CA1. 'Startle response', which 
Table 1 Twenty-eight schizophrenia susceptibility genes are also implicated in other neuropsychiatric disorders that exhibit neuroanatomical or functional abnormalities in the hippocampal formation

\begin{tabular}{|c|c|c|c|c|c|c|c|c|c|c|c|c|c|c|c|c|c|c|}
\hline \multirow[t]{3}{*}{ Genes } & & & & & & & & & \multicolumn{10}{|c|}{ Significant differences in expression between newborn and adult monkeys } \\
\hline & \multicolumn{8}{|c|}{ Diseases } & \multicolumn{5}{|c|}{ Adult $>$ newborn } & \multicolumn{5}{|c|}{ Newborn > adult } \\
\hline & $S C Z$ & $E P I$ & $A S D$ & $D E P$ & $P S Y$ & $B P$ & $A L Z$ & WIL & $E C$ & $D G$ & CA3 & $C A 1$ & Sub & $E C$ & $D G$ & CA3 & CA1 & Sub \\
\hline SLC6A4 & $x$ & $x$ & $x$ & $x$ & $x$ & & & & & & & & & & & & & \\
\hline BDNF & $x$ & $x$ & & $x$ & & $x$ & & & & & & & & & & & $x$ & $x$ \\
\hline APOE & $x$ & $x$ & & $x$ & & & $x$ & & & & & & & & $x$ & $x$ & $x$ & \\
\hline SLC6A3 & $x$ & & & $x$ & $x$ & $x$ & & & & & & & & & & & & \\
\hline MTHFR & $x$ & $x$ & & $x$ & & & & & & & & & & & & & & \\
\hline DISC1 & $x$ & & $x$ & & & $x$ & & & & & & & & & & & & \\
\hline CHRNB2 & $x$ & $x$ & & & & & $x$ & & & $x$ & & & & & $x$ & & & \\
\hline HTR2A & $x$ & & & $x$ & $x$ & & & & & & & & & & & & & \\
\hline MAOA & $x$ & & & & $x$ & & & & & $x$ & & & & & & $x$ & $x$ & \\
\hline DRD2 & $x$ & & & & $x$ & & & & & & & & & & $x$ & & $x$ & \\
\hline SLC1A2 & $x$ & & & & $x$ & & & & $x$ & & & & $x$ & & $x$ & $x$ & $x$ & \\
\hline COMT & $x$ & & & & $x$ & & & & & & & & & $x$ & $x$ & $x$ & $x$ & \\
\hline AR & $x$ & & & & $x$ & & & & & & & $x$ & & & & & & \\
\hline GABBR1 & $x$ & $x$ & & & & & & & & & & & & & & $x$ & $x$ & \\
\hline GABRG2 & $x$ & $x$ & & & & & & & $x$ & $x$ & & & & & & $x$ & $x$ & \\
\hline IL10 & $x$ & $x$ & & & & & & & & & & & & & & & & \\
\hline IL1B & $x$ & $x$ & & & & & & & & & $x$ & $x$ & & & & & & \\
\hline TNF & $x$ & $x$ & & & & & & & & & & & & & & & & \\
\hline $\mathrm{AHI} 1$ & $x$ & & $x$ & & & & & & & & & & & & & $x$ & & $x$ \\
\hline DRD5 & $x$ & & $x$ & & & & & & & & & & & & & $x$ & $x$ & \\
\hline FOXP2 & $x$ & & $x$ & & & & & & & & & & & & & & & $x$ \\
\hline PTPRZ1 & $x$ & & $x$ & & & & & & & $x$ & & & & & $x$ & $x$ & $x$ & \\
\hline RELN & $x$ & & $x$ & & & & & & & & & & & & $x$ & & & \\
\hline GRM3 & $x$ & & & & & $x$ & & & & & & & & $x$ & $x$ & & & \\
\hline DAO & $x$ & & & & & $x$ & & & & & & & & & & & $x$ & \\
\hline GRIN2B & $x$ & & & & & $x$ & & & & & & & & & $x$ & $x$ & $x$ & \\
\hline STX1A & $x$ & & & & & & & $x$ & & & & & & & & $x$ & & $x$ \\
\hline SLC18A1 & $x$ & & & $x$ & & & & & & & $x$ & & & & & & & \\
\hline Total number & 28 & 10 & 7 & 7 & 8 & 6 & 2 & 1 & 2 & 4 & 2 & 2 & 1 & 2 & 9 & 11 & 12 & 4 \\
\hline Percentage & & $36 \%$ & $25 \%$ & $25 \%$ & $29 \%$ & $21 \%$ & $7 \%$ & $4 \%$ & $7 \%$ & $14 \%$ & $7 \%$ & $7 \%$ & $4 \%$ & $7 \%$ & $32 \%$ & $39 \%$ & $43 \%$ & $14 \%$ \\
\hline
\end{tabular}

Abbreviations: ALZ, Alzheimer's disease; ASD, autism spectrum disorder; BP, bipolar disorder; DEP, major depressive disorder; DG, dentate gyrus; EC, entorhinal cortex; EPI, temporal lobe epilepsy; PSY, psychopathy antisocial personality disorder; SCZ, schizophrenia; Sub, subiculum; WIL, Williams syndrome.
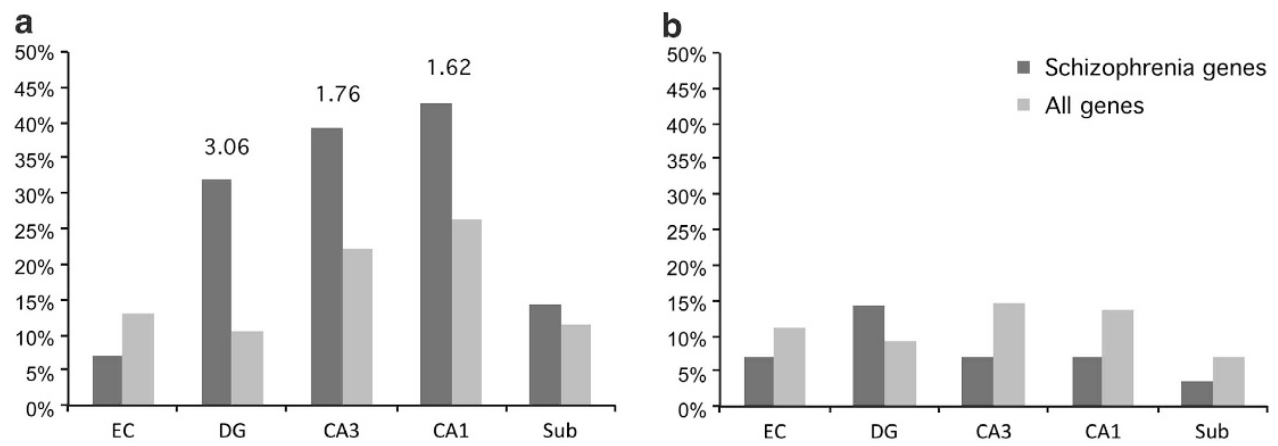

Figure 3 Percentages of schizophrenia susceptibility genes also involved in other diseases, which are regulated in distinct hippocampal regions from birth to adulthood. (a) Decreased expression. (b) Increased expression. Schizophrenia susceptibility genes also involved in other diseases (28; dark gray); protein-coding human genes (20 741; light gray). DG, dentate gyrus; EC, entorhinal cortex; Sub, subiculum.

is identified as a functional group in the dentate gyrus and CA1, is not related directly to any known schizophrenic symptoms, but it is associated with the impairment in prepulse inhibition observed in schizophrenics. The most important functional process identified in the schizophrenia susceptibility genes upregulated in both CA3 and CA1 is related to 'inflammatory response', which might produce an imbalance in $\mathrm{N}$-methyl-D-aspartate (NMDA)-mediated glutamatergic neurotransmission.
Multiple pathologies. The involvement of genes in different pathologies suggests that they contribute to alterations of nonspecific processes implicated in all these disorders. Here we consider the function and the expression patterns of four of these genes in order to characterize the fundamental processes that might link them to these disorders.

$A P O E$. The role of $A P O E$ in the regulation of glutamatergic neurotransmission might explain its implication in schizophrenia, ${ }^{51}$ major depressive disorder in the elderly, ${ }^{52,53}$ 
Table 2 Functional analyses of schizophrenia susceptibility genes exhibiting differences in expression between newborn and adult monkeys in any one of five distinct hippocampal regions

\begin{tabular}{|c|c|c|c|c|}
\hline \multicolumn{5}{|c|}{ Adult $>$ newborn } \\
\hline$E C$ & $D G$ & CA3 & $C A 1$ & Sub \\
\hline Cell-cell signaling & Axogenesis & Cell-cell signaling & Cell-cell signaling & Apoptosis \\
\hline Synaptic transmission & Neuron differentiation & $\begin{array}{l}\text { Inflammatory } \\
\text { response }\end{array}$ & Inflammatory response & Cell cycle \\
\hline \multirow[t]{5}{*}{$\begin{array}{l}\text { Transmission of nerve } \\
\text { impulse }\end{array}$} & $\begin{array}{l}\text { Regulation of neurotransmit- } \\
\text { ter levels }\end{array}$ & $\begin{array}{l}\text { Neurotransmitter } \\
\text { transport }\end{array}$ & & Cell-cell signaling \\
\hline & Synaptic transmission & Response to drug & & $\begin{array}{l}\text { Positive regulation of } \\
\text { transport }\end{array}$ \\
\hline & $\begin{array}{l}\text { Transmission of nerve } \\
\text { impulse }\end{array}$ & & & Response to drug \\
\hline & Vesicle-mediated transport & & & $\begin{array}{l}\text { Response to endogen- } \\
\text { ous stimulus } \\
\text { Tyrosine kinase signal- } \\
\text { ing pathway }\end{array}$ \\
\hline & \multicolumn{3}{|c|}{ Newborn $>$ adult } & \\
\hline Cell adhesion & Axogenesis & Apoptosis & Calcium signaling pathway & Cell adhesion \\
\hline $\begin{array}{l}\text { Glutamate } \\
\text { neurotransmission }\end{array}$ & Cell adhesion & Associative learning & Cell cycle & Cell differentiation \\
\hline Inflammatory response & Cell migration & $\begin{array}{l}\text { Dendrite } \\
\text { morphogenesis }\end{array}$ & Cyclic nucleotide & $\begin{array}{l}\text { Cell migration } \\
\text { monoamine }\end{array}$ \\
\hline Neurotransmission & Cyclic nucleotide & G-protein signaling & Dendrite morphogenesis & Glial cell differentiation \\
\hline $\begin{array}{l}\text { Regulation of mem- } \\
\text { brane potential }\end{array}$ & G-protein signaling & $\begin{array}{l}\text { Glutamate } \\
\text { neurotransmission }\end{array}$ & G-protein signaling & $\begin{array}{l}\text { Neurogenesis response } \\
\text { to synaptic transmission }\end{array}$ \\
\hline Endogenous stimulus & Glial cell differentiation & $\begin{array}{l}\text { Inflammatory } \\
\text { response }\end{array}$ & GABA signaling pathway & $\begin{array}{l}\text { Transmission of nerve } \\
\text { impulse }\end{array}$ \\
\hline $\begin{array}{l}\text { Response to external } \\
\text { stimulus }\end{array}$ & Gliogenesis & $\begin{array}{l}\text { Monoamine } \\
\text { neurotransmission }\end{array}$ & Glial cell differentiation & \\
\hline $\begin{array}{l}\text { Response to organic } \\
\text { nitrogen }\end{array}$ & $\begin{array}{l}\text { Glutamate } \\
\text { neurotransmission }\end{array}$ & Neurogenesis & $\begin{array}{l}\text { Glutamate } \\
\text { neurotransmission }\end{array}$ & \\
\hline Synaptic transmission & Lipid catabolic process & $\begin{array}{l}\text { Neuron } \\
\text { differentiation }\end{array}$ & $\begin{array}{l}\text { Monoamine } \\
\text { neurotransmission }\end{array}$ & \\
\hline \multirow[t]{13}{*}{$\begin{array}{l}\text { Transmission of nerve } \\
\text { impulse }\end{array}$} & $\begin{array}{l}\text { Monoamine } \\
\text { neurotransmission }\end{array}$ & Neuron projection & Neurogenesis & \\
\hline & $\begin{array}{l}\text { Multicellular organismal } \\
\text { response to stress }\end{array}$ & $\begin{array}{l}\text { Nitrogen compound } \\
\text { metabolic process }\end{array}$ & Neuron differentiation & \\
\hline & Neurogenesis & Notch pathway & Neuron projection & \\
\hline & Neuron differentiation & $\begin{array}{l}\text { Regulation of mem- } \\
\text { brane potential }\end{array}$ & $\begin{array}{l}\text { Nitrogen compound metabolic } \\
\text { process }\end{array}$ & \\
\hline & $\begin{array}{l}\text { Nitrogen compound meta- } \\
\text { bolic process }\end{array}$ & Synaptic plasticity & Peptidyl-tyrosine modification & \\
\hline & $\begin{array}{l}\text { Phosphoinositide-mediated } \\
\text { signaling }\end{array}$ & Synaptic transmission & $\begin{array}{l}\text { Regulation of membrane } \\
\text { potential }\end{array}$ & \\
\hline & $\begin{array}{l}\text { Regulation of membrane } \\
\text { potential }\end{array}$ & $\begin{array}{l}\text { Transmission of nerve } \\
\text { impulse }\end{array}$ & Regulation of transcription & \\
\hline & Response to nutrient levels & $\begin{array}{l}\text { Tyrosine kinase sig- } \\
\text { naling pathway }\end{array}$ & Response to drug & \\
\hline & Startle response & & Response to organic nitrogen & \\
\hline & Synaptic plasticity & & Startle response & \\
\hline & Synaptic transmission & & Synaptic plasticity & \\
\hline & $\begin{array}{l}\text { Transmission of nerve } \\
\text { impulse }\end{array}$ & & Synaptic transmission & \\
\hline & & & $\begin{array}{l}\text { Transmission of nerve impulse } \\
\text { Tyrosine kinase signaling } \\
\text { pathway }\end{array}$ & \\
\hline
\end{tabular}

DG, dentate gyrus; EC, entorhinal cortex; Sub, subiculum.

Groups in bold are highlighted in the Results and Discussion sections.

temporal lobe epilepsy ${ }^{26}$ and Alzheimer's disease. ${ }^{54}$ Indeed, one of the main physiological processes influenced by different alleles of $A P O E$ is the sequestration of NMDA and AMPA (alpha-amino-3-hydroxy-5-methyl-4-isoxazolpropionate) receptors in intracellular compartments, which could, in turn, lead to changes in long term potentiation (LTP) induction and neuronal degeneration. ${ }^{55}$
MTHFR. A mutation of the gene MTHFR, which encodes the enzyme methylene-tetrahydrofolate reductase involved in the homocysteine metabolic pathway, might indirectly impact glutamatergic transmission, increasing nonspecifically the risk for different disorders. Indeed, MTHFR contributes to the regulation of $R E L N,{ }^{56}$ whose expression is decreased in the hippocampus of subjects suffering from 
schizophrenia and major depressive disorder. ${ }^{57}$ RELN binds to the receptor APOER2 (which is also a receptor for APOE), and might thus similarly modulate glutamatergic neurotransmission.

$B D N F$. Dysregulation of $B D N F$, the gene coding for the ubiquitous brain-derived neurotrophic factor, might also lead to alterations of glutamatergic neurotransmission, as recently shown in the human hippocampus. ${ }^{58}$ BDNF enhances glutamate release, the frequency of miniature Excitatory Postsynaptic Currents (mEPSCs), NMDA receptor activity and the phosphorylation of NMDA receptor subunits. ${ }^{59}$ BDNF expression is regulated by synaptic activity; it does not appear to mediate changes in synaptic efficacy, but instead contributes to the modulation of the capability of glutamatergic synapses to undergo LTP and long term depression (LTD)..$^{60}$

SLC6A4. SLC6A4 codes for the high-affinity serotonin transporter localized presynaptically, which has been implicated in schizophrenia, ${ }^{61}$ temporal lobe epilepsy, ${ }^{62}$ autism spectrum disorder, major depressive disorder ${ }^{36,63}$ and antisocial personality disorder. This suggests that a dysregulation of serotonin levels is common to different neuropsychiatric disorders.

\section{Discussion}

We found that schizophrenia susceptibility genes are significantly more regulated than other genes in the dentate gyrus, CA3 and CA1 from birth to adulthood. These findings are consistent with the hypothesis that hippocampal subfield dysfunctions could underlie psychotic manifestations in schizophrenia. ${ }^{20,21}$ We discuss the possible relations between gene dysregulation, abnormal hippocampal development, neuropathological findings and clinical symptoms observed in schizophrenics.

Glutamatergic neurotransmission. Glutamatergic pathways are most prominently, although not exclusively, affected in schizophrenia, ${ }^{19}$ and alterations of glutamatergic neurotransmission in the hippocampal formation is thought to be associated with some psychotic symptoms observed in schizophrenia. ${ }^{20,21}$ In healthy subjects, ketamine, an NMDA receptor antagonist, produces psychotic symptoms including hallucinations and thought disorders, depersonalization and derealization, as well as negative symptoms like apathy. ${ }^{64}$ Ketamine decreases cerebral blood flow in the hippocampus of both control subjects and schizophrenics, reflecting a deactivation of excitatory glutamatergic synapses; this effect is greater in schizophrenics than in controls. ${ }^{65}$ Dysfunction of glutamate neurotransmission might also be linked to hippocampus-dependent long-term memory impairments observed in schizophrenics. ${ }^{66-69}$ Interestingly, inhibition of glutamate neurotransmission by ketamine infusion in control subjects disrupts verbal recognition memory and decreases word event-related potentials in the anterior medial temporal lobe. $^{67}$

Accordingly, schizophrenia susceptibility genes regulated in the dentate gyrus, CA3 and CA1 from birth to adulthood belong to functional groups including neurotransmission, and involve more specifically the glutamatergic system. Decreases in AMPA, NMDA and kainate receptor subunits expression have been shown in the dentate gyrus and CA3 of schizophrenics. ${ }^{49}$ In contrast, an increase of GRIN2B mRNA expression was reported in several hippocampal regions. ${ }^{21}$

An important group of schizophrenia susceptibility genes regulated in both CA3 and CA1 is related to 'inflammatory response'. Prenatal infection has been proposed to facilitate the early sensitization of the immune system, which might lead to an increased risk for schizophrenia. ${ }^{70}$ Mechanistically, immune system dysfunction might lead to an increase of kynurenine observed in schizophrenic patients. ${ }^{70}$ Kynurenine, is a metabolite of tryptophan and is the only known endogenous NMDA receptor antagonist. Inhibition of glutamatergic transmission in the hippocampus might lead to psychotic symptoms like depersonalization, derealization, hallucinations, thought disorders and apathy. ${ }^{64,70}$

Altogether, these findings suggest that an overall decreased neurotransmission in the main excitatory pathways, as well as a modulation of glutamatergic receptors activity, might lead to the dysfunction of glutamatergic circuits within the hippocampal formation. ${ }^{20}$ We discuss specific findings in the dentate gyrus, CA3 and CA1, in turn.

The dentate gyrus. Abnormal expression of schizophrenia susceptibility genes involved in neurogenesis could be linked to the reduced cell proliferation reported in the dentate gyrus of schizophrenics. ${ }^{71}$ However, the absence of obvious changes in the total number of neurons ${ }^{19}$ suggests that pathogenic factors that induce dentate gyrus dysfunction, and have a role in schizophrenia, are unlikely to impact the initial phase of postnatal developmental neurogenesis and neuronal addition in the granule cell layer (which might correspond to at least the first four postnatal years in humans). ${ }^{10}$ Schizophrenia pathology, however, might impact more subtle aspects of neurogenesis and dentate gyrus function at later ages, ${ }^{20}$ without resulting in obvious morphological signs of neuropathology. ${ }^{19}$ Indeed, the inclusion of the functional group axogenesis in the schizophrenia susceptibility genes regulated in the dentate gyrus might be associated with the observations that there are fewer synaptic contacts formed by dentate mossy fiber terminals in CA3 and that the branched spines of CA3 pyramidal neurons are smaller in schizophrenics. ${ }^{50}$ In addition, reduced dysbindin-1 (coded by the gene DTNBP1) expression in the inner molecular layer of the dentate gyrus is also consistent with alterations of intrinsic dentate gyrus pathways. ${ }^{19,72}$

Disruption of one of the basic functions assigned to the dentate gyrus, pattern separation, ${ }^{73}$ has not been reported specifically in schizophrenics. However, disruption of the dentate gyrus projections to CA3 might impact other functions supported by CA3 or CA1. Changes in CA3 mossy fiber synapses in schizophrenics may reduce the functional contribution of the dentate gyrus to hippocampus-dependent memory processes, diminishing dentate gyrus-mediated pattern separation and possibly contributing to or potentiating the CA3-mediated process of pattern completion, leading to the loosening of association. As proposed by others, ${ }^{20,21}$ the relative shift toward pattern completion could advantage inappropriate associations, generate false or illogical memories, and create a susceptibility to psychosis. 
CA3. Schizophrenia susceptibility genes regulated in CA3 during postnatal development were included in the functional groups: dendritic morphology, synaptic plasticity and transmission, neuron projection. This is consistent with the alterations in glutamatergic and GABAergic synapses observed in CA3. ${ }^{49}$ Specifically, the expression of the glutamate receptor subunits GluA1 (GRIA1), GluA2 (GRIA2), GluN1 (GRIN1), GluK5 (GRIK5) and the vesicular glutamate transporter VGLUT1 (SLC17A7) is lower in the CA3 of schizophrenics, as compared with controls. ${ }^{49}$ In contrast, there is a higher expression of GRIN2B mRNA (coding for the GluN2B receptor subunit), ${ }^{21}$ a schizophrenia susceptibility gene. A corresponding increase in GluN2B-containing NMDA receptors in CA3 would be consistent with the symptom of loosening of association observed in schizophrenia. Indeed, NMDA receptors containing the GluN2B subunit, exhibit longer opening time than other NMDA receptors. GRIN2B is normally downregulated during postnatal development, which might contribute to the emergence of more selective memory function in adult normal individuals. In adult schizophrenics, increased expression of GluN2B might contribute to the formation of less specific, illogical associations of information.

Accordingly, another functional group of schizophrenia susceptibility genes regulated in CA3 is 'associative learning'. CA3 is thought to be central for the process of pattern completion. ${ }^{74}$ As discussed above, disturbance of pattern completion might contribute to the loosening of association observed in schizophrenics. ${ }^{75}$ The majority of schizophrenia susceptibility genes exhibiting lower expression in adults than in newborns in CA3, show a lower expression in adulthood than at any other age. This suggests that CA3 dysfunction might manifest at relatively late developmental stages. This is in agreement with the fact that looseness of association is associated primarily with the acute stage of schizophrenia, ${ }^{76}$ which first occurs in late adolescence or early adulthood.

In sum, CA3 pathology might be especially involved in one of the cardinal characteristics of schizophrenia: the loosening of association. The fact that a majority of schizophrenia susceptibility genes exhibit a downregulation of expression relatively late during postnatal development in CA3 is consistent with a late onset and diagnosis of schizophrenia.

CA1. Schizophrenia susceptibility genes regulated in CA1 were included in the functional groups: neurotransmission, dendrite morphology, synaptic plasticity and axogenesis. However, these genes exhibited a downregulation of their expression earlier in $\mathrm{CA} 1$, as compared with $\mathrm{CA} 3$, and might thus be linked to the early appearance of delusions and other prodromal symptoms. CA1 hyperactivation is thought to result from a dysregulation in dopamine neuromodulation, functionally isolating CA1 from its direct sensory inputs from the entorhinal cortex, and thus leading to a relative increase in the importance of its inputs from CA3. As shown in in vitro slice preparations in rats, dopamine inhibits CA1 pyramidal cells' response to perforant pathway stimulation but not to CA3 Schaffer collateral stimulation. ${ }^{77}$ In vivo, this might reduce CA1's response to specific sensory information coming from the entorhinal cortex and lead to a discordant CA1 comparison of the direct sensory input (via projections from the entorhinal cortex) and the predictions based on the contents of long-term memory provided by CA3. CA1 dysregulation, whose early onset is associated with prodromal symptoms, might be exacerbated when disrupted CA3 function manifests at later ages, leading to the progression into a more typical symptomatology compatible with the typical diagnosis of schizophrenia.

Accordingly, a high-resolution functional imaging study recently revealed an increase in cerebral blood flow in CA1 of schizophrenics. ${ }^{78}$ Although brain activation also changed in other brain regions, symptom severity correlated with abnormal activity only in CA1. In addition, CA1 hyperactivity signal was predictive of the development of psychosis in a prodromal group (comprises patients who met ultra-high-risk criteria for psychosis) and correlated positively with delusions. This suggests that CA1 hyperactivity might contribute to the generation of delusions and other positive symptoms. ${ }^{78}$

\section{Conclusion}

We found that schizophrenia susceptibility genes are significantly more regulated than other genes, and differentially regulated, in the dentate gyrus, CA3 and CA1 from birth to adulthood. These findings are consistent with the hypothesis that the developmental dysregulation of schizophrenia susceptibility genes in distinct hippocampal subfields might be related to the emergence of specific symptoms. A number of schizophrenia susceptibility genes including $A P O E, B D N F$, MTHFR and SLC6A4 are involved in other disorders, and thus likely contribute to nonspecific changes in hippocampal structure and function that must be combined with the dysregulation of other genes in order to lead to schizophrenia pathogenesis.

\section{Conflict of interest}

The authors declare no conflict of interest.

Acknowledgements. This work was supported by the Swiss National Science Foundation (PP00A-106701, PP00P3-124536/1) and the National Alliance for Research on Schizophrenia and Depression (NARSAD). We thank Jeff Gregg, Ryan Davis and Steven Sugden for their contribution to the early stages of this research program.

1. Nelson MD, Saykin AJ, Flashman LA, Riordan HJ. Hippocampal volume reduction in schizophrenia as assessed by magnetic resonance imaging: a meta-analytic study. Arch Gen Psychiatry 1998; 55: 433-440.

2. Bauman ML, Kemper TL. Neuroanatomic observations of the brain in autism: a review and future directions. Int J Dev Neurosci 2005; 23: 183-187.

3. Seidenberg M, Kelly KG, Parrish J, Geary E, Dow C, Rutecki P et al. Ipsilateral and contralateral MRI volumetric abnormalities in chronic unilateral temporal lobe epilepsy and their clinical correlates. Epilepsia 2005; 46: 420-430.

4. Leverenz JB, Raskind MA. Early amyloid deposition in the medial temporal lobe of young Down syndrome patients - a regional quantitative analysis. Exp Neurol 1998; 150: 296-304.

5. Meyer-Lindenberg A, Mervis CB, Sarpal D, Koch P, Steele S, Kohn P et al. Functional, structural, and metabolic abnormalities of the hippocampal formation in Williams syndrome. J Clin Invest 2005; 115: 1888-1895.

6. Boccardi M, Ganzola R, Rossi R, Sabattoli F, Laakso MP, Repo-Tiihonen E et al. Abnormal hippocampal shape in offenders with psychopathy. Hum Brain Mapp 2010; 31: 438-447.

7. Ng WX, Lau IY, Graham S, Sim K. Neurobiological evidence for thalamic, hippocampal and related glutamatergic abnormalities in bipolar disorder: a review and synthesis. Neurosci Biobehav Rev 2009; 33: 336-354

8. Sheline YI. 3D MRI studies of neuroanatomic changes in unipolar major depression: the role of stress and medical comorbidity. Biol Psychiatry 2000; 48: 791-800. 
9. Hampel H, Burger K, Teipel SJ, Bokde AL, Zetterberg H, Blennow K. Core candidate neurochemical and imaging biomarkers of Alzheimer's disease. Alzheimers Dement 2008; 4: 38-48.

10. Lavenex P. Functional anatomy, development and pathology of the hippocampus. In: Bartsch T(ed)Clinical Neurobiology of the Hippocampus Thorsten Bartsch edn University Press: Oxford, 2012.

11. Maric NP, Svrakic DM. Why schizophrenia genetics needs epigenetics: a review. Psychiatr Danub 2012; 24: 2-18.

12. Gottesman II. Schizophrenia Genesis: The Origins of Madness 1991.

13. Gottesman II, Shields J. A critical review of recent adoption, twin, and family studies of schizophrenia: behavioral genetics perspectives. Schizophr Bull 1976; 2: 360-401.

14. Allen NC, Bagade S, McQueen MB, loannidis JP, Kavvoura FK, Khoury MJ et al. Systematic meta-analyses and field synopsis of genetic association studies in schizophrenia: the SzGene database. Nat Genet 2008; 40: 827-834.

15. Sun J, Jia P, Fanous AH, Webb BT, van den Oord EJ, Chen X et al. A multi-dimensional evidence-based candidate gene prioritization approach for complex diseases-schizophrenia as a case. Bioinformatics 2009; 25: 2595-6602.

16. White T, Anjum A, Schulz SC. The schizophrenia prodrome. Am J Psychiatry 2006; 163 : 376-380.

17. Steen RG, Mull C, McClure R, Hamer RM, Lieberman JA. Brain volume in first-episode schizophrenia: systematic review and meta-analysis of magnetic resonance imaging studies. Br J Psychiatry 2006; 188: 510-518

18. Sismanlar SG, Anik Y, Coskun A, Agaoglu B, Karakaya I, Yavuz Cl. The volumetric differences of the fronto-temporal region in young offspring of schizophrenic patients. Eur Child Adolesc Psychiatry 2010; 19: 151-157.

19. Harrison PJ. The hippocampus in schizophrenia: a review of the neuropathological evidence and its pathophysiological implications. Psychopharmacology (Berl) 2004; 174 151-162.

20. Tamminga $C A, S t a n A D$, Wagner $A D$. The hippocampal formation in schizophrenia. Am J Psychiatry 2010; 167: 1178-1193.

21. Tamminga CA, Southcott $S$, Sacco $C$, Wagner AD, Ghose S. Glutamate dysfunction in hippocampus: relevance of dentate gyrus and CA3 signaling. Schizophr Bull 2012.

22. Lavenex P, Sugden SG, Davis RR, Gregg JP, Lavenex PB. Developmental regulation of gene expression and astrocytic processes may explain selective hippocampal vulnerability. Hippocampus 2011; 21: 142-149.

23. Favre GA, Banta Lavenex $P$, Lavenex $P$. miRNA regulation of gene expression: a predictive bioinformatics analysis in the postnatally developing monkey hippocampus. PLoS One 2012; 7: e43435.

24. Benjamini $Y$, Hochberg $Y$. Controlling the false discovery rate: a practical and powerful approach to multiple testing. JR Statist Soc B 1995; 57: 289-300.

25. Huang da W, Sherman BT, Lempicki RA. Systematic and integrative analysis of large gene lists using DAVID bioinformatics resources. Nat Protoc 2009; 4: 44-57.

26. Tan NC, Berkovic SF. The Epilepsy Genetic Association Database (epiGAD): analysis of 165 genetic association studies, 1996-2008. Epilepsia 2010; 51: 686-689.

27. Noebels JL. The biology of epilepsy genes. Annu Rev Neurosci 2003; 26: 599-625.

28. Gunter TD, Vaughn MG, Philibert RA. Behavioral genetics in antisocial spectrum disorders and psychopathy: a review of the recent literature. Behav Sci Law 2010; 28: 148-173.

29. Salekin R, Lynam D. Handbook of Child and Adolescent Psychopathy 2010.

30. Raine A. From genes to brain to antisocial behavior. Curr Directions Psychol Sci 2008; 17 323-328.

31. Muhle R, Trentacoste SV, Rapin I. The genetics of autism. Pediatrics 2004; 113: e472-e486.

32. Abrahams BS, Geschwind DH. Advances in autism genetics: on the threshold of a new neurobiology. Nat Rev Genet 2008; 9: 341-355.

33. Freitag CM, Staal W, Klauck SM, Duketis E, Waltes R. Genetics of autistic disorders: review and clinical implications. Eur Child Adolesc Psychiatry 2010; 19: 169-178.

34. Anney R, Klei L, Pinto D, Regan R, Conroy J, Magalhaes TR et al. A genome-wide scan for common alleles affecting risk for autism. Hum Mol Genet 2010; 19: 4072-4082.

35. Shyn SI, Shi J, Kraft JB, Potash JB, Knowles JA, Weissman MM et al. Novel loci for major depression identified by genome-wide association study of sequenced treatment alternatives to relieve depression and meta-analysis of three studies. Mol Psychiatry 2009; 16: 202-215.

36. Lopez-Leon S, Janssens AC, Gonzalez-Zuloeta Ladd AM, Del-Favero J, Claes SJ, Oostra BA et al. Meta-analyses of genetic studies on major depressive disorder. Mol Psychiatry 2008; 13: 772-785.

37. Lohoff FW. Overview of the genetics of major depressive disorder. Curr Psychiatry Rep 2010; 12: 539-546.

38. Shyn SI, Hamilton SP. The genetics of major depression: moving beyond the monoamine hypothesis. Psychiatr Clin North Am 2010; 33: 125-140.

39. Baum AE, Akula N, Cabanero M, Cardona I, Corona W, Klemens B et al. A genome-wide association study implicates diacylglycerol kinase eta (DGKH) and several other genes in the etiology of bipolar disorder. Mol Psychiatry 2008; 13: 197-207.

40. Cichon S, Muhleisen TW, Degenhardt FA, Mattheisen M, Miro X, Strohmaier J et al. Genome-wide association study identifies genetic variation in neurocan as a susceptibility factor for bipolar disorder. Am J Hum Genet 2011; 88: 372-381.

41. Djurovic S, Gustafsson O, Mattingsdal M, Athanasiu L, Bjella T, Tesli M et al. A genomewide association study of bipolar disorder in Norwegian individuals, followed by replication in Icelandic sample. J Affect Disord 2010; 126: 312-316.
42. Sklar P, Smoller JW, Fan J, Ferreira MA, Perlis RH, Chambert $\mathrm{K}$ et al. Whole-genome association study of bipolar disorder. Mol Psychiatry 2008; 13: 558-569.

43. Martinowich K, Schloesser RJ, Manji HK. Bipolar disorder: from genes to behavior pathways. J Clin Invest 2009; 119: 726-736.

44. Schulze TG. Genetic research into bipolar disorder: the need for a research framework that integrates sophisticated molecular biology and clinically informed phenotype characterization. Psychiatr Clin North Am 2010; 33: 67-82.

45. Bettens K, Sleegers K, Van Broeckhoven C. Current status on Alzheimer disease molecular genetics: from past, to present, to future. Hum Mol Genet 2010; 19: R4-R11.

46. Ertekin-Taner N. Genetics of Alzheimer disease in the pre- and post-GWAS era. Alzheimers Res Ther 2010; 2: 3.

47. Meyer-Lindenberg A, Mervis CB, Berman KF. Neural mechanisms in Williams syndrome: a unique window to genetic influences on cognition and behaviour. Nat Rev Neurosci 2006; 7: 380-393.

48. Rachidi M, Lopes C. Molecular and cellular mechanisms elucidating neurocognitive basis of functional impairments associated with intellectual disability in Down syndrome. Am J Intellect Dev Disabil 2010; 115: 83-112.

49. Harrison PJ, Law AJ, Eastwood SL. Glutamate receptors and transporters in the hippocampus in schizophrenia. Ann N Y Acad Sci 2003; 1003: 94-101.

50. Kolomeets NS, Orlovskaya DD, Uranova NA. Decreased numerical density of CA3 hippocampal mossy fiber synapses in schizophrenia. Synapse 2007; 61: 615-621.

51. Harrington CR, Roth M, Xuereb JH, McKenna PJ, Wischik CM. Apolipoprotein E type epsilon 4 allele frequency is increased in patients with schizophrenia. Neurosci Lett 1995 202: 101-104.

52. Traykov L, Bayle AC, Latour F, Lenoir H, Seux ML, Hanon $O$ et al. Apolipoprotein epsilon4 allele frequency in elderly depressed patients with and without cerebrovascular disease. J Neurol Sci 2007; 257: 280-283

53. Yen YC, Rebok GW, Gallo JJ, Yang MJ, Lung FW, Shih CH. ApoE4 allele is associated with late-life depression: a population-based study. Am J Geriatr Psychiatry 2007; 15: 858-868.

54. Saunders AM, Strittmatter WJ, Schmechel D, George-Hyslop PH, Pericak-Vance MA, Joo $\mathrm{SH}$ et al. Association of apolipoprotein $\mathrm{E}$ allele epsilon 4 with late-onset familial and sporadic Alzheimer's disease. Neurology 1993; 43: 1467-1472.

55. Chen $Y$, Durakoglugil MS, Xian X, Herz J. ApoE4 reduces glutamate receptor function and synaptic plasticity by selectively impairing ApoE receptor recycling. Proc Natl Acad Sci USA 2010; 107: 12011-12016.

56. Chen Z, Schwahn BC, Wu Q, He X, Rozen R. Postnatal cerebellar defects in mice deficient in methylenetetrahydrofolate reductase. Int J Dev Neurosci 2005; 23: 465-474.

57. Fatemi SH, Earle JA, McMenomy T. Reduction in Reelin immunoreactivity in hippocampus of subjects with schizophrenia, bipolar disorder and major depression. Mol Psychiatry 2000; 5: 571 .

58. Gruber $\mathrm{O}$, Hasan A, Scherk $H$, Wobrock T, Schneider-Axmann T, Ekawardhani S et al. Association of the brain-derived neurotrophic factor val66met polymorphism with magnetic resonance spectroscopic markers in the human hippocampus: in vivo evidence for effects on the glutamate system. Eur Arch Psychiatry Clin Neurosci 2011; 262: 23-31.

59. Martin JL, Finsterwald C. Cooperation between BDNF and glutamate in the regulation of synaptic transmission and neuronal development. Communicative \& integrative biology 2011; 4: 14-16.

60. Poo MM. Neurotrophins as synaptic modulators. Nat Rev Neurosci 2001; 2: 24-32.

61. Fan JB, Sklar P. Meta-analysis reveals association between serotonin transporter gene STin2 VNTR polymorphism and schizophrenia. Mol Psychiatry 2005; 10: 928-938 891 .

62. Manna I, Labate A, Gambardella A, Forabosco P, La Russa A, Le Piane E et al. Serotonin transporter gene $(5-\mathrm{Htt})$ : association analysis with temporal lobe epilepsy. Neurosci Lett 2007; 421: 52-56

63. Kilpatrick DG, Koenen KC, Ruggiero KJ, Acierno R, Galea S, Resnick HS et al. The serotonin transporter genotype and social support and moderation of posttraumatic stress disorder and depression in hurricane-exposed adults. Am J Psychiatry 2007; 164 1693-1699.

64. Vollenweider FX, Leenders KL, Scharfetter C, Antonini A, Maguire P, Missimer J et al. Metabolic hyperfrontality and psychopathology in the ketamine model of psychosis using positron emission tomography (PET) and [18F]fluorodeoxyglucose (FDG). Eur Neuropsychopharmacol 1997; 7: 9-24.

65. Medoff DR, Holcomb HH, Lahti AC, Tamminga CA. Probing the human hippocampus using rCBF: contrasts in schizophrenia. Hippocampus 2001; 11: 543-550.

66. Johnson SC, Saykin AJ, Flashman LA, McAllister TW, Sparling MB. Brain activation on fMRI and verbal memory ability: functional neuroanatomic correlates of CVLT performance. J Int Neuropsychol Soc 2001; 7: 55-62.

67. Grunwald T, Beck H, Lehnertz K, Blumcke I, Pezer N, Kurthen M et al. Evidence relating human verbal memory to hippocampal N-methyl-D-aspartate receptors. Proc Natl Acad Sci USA 1999; 96: 12085-12089.

68. Aleman A, Hijman R, de Haan EH, Kahn RS. Memory impairment in schizophrenia: a metaanalysis. Am J Psychiatry 1999; 156: 1358-1366.

69. Bhatt R, Laws KR, McKenna PJ. False memory in schizophrenia patients with and without delusions. Psychiatry Res 2010; 178: 260-265.

70. Muller N, Schwarz MJ. [Immunology in schizophrenic disorders]. Nervenarzt 2007; 78 253-256 258-260, 262-263. 
71. Reif A, Schmitt A, Fritzen S, Lesch KP. Neurogenesis and schizophrenia: dividing neurons in a divided mind? Eur Arch Psychiatry Clin Neurosci 2007; 257: 290-299.

72. Talbot K, Eidem WL, Tinsley CL, Benson MA, Thompson EW, Smith RJ et al. Dysbindin-1 is reduced in intrinsic, glutamatergic terminals of the hippocampal formation in schizophrenia. J Clin Invest 2004; 113: 1353-1363.

73. McHugh TJ, Jones MW, Quinn JJ, Balthasar N, Coppari R, Elmquist JK et al. Dentate gyrus NMDA receptors mediate rapid pattern separation in the hippocampal network. Science 2007; 317: 94-99.

74. Nakazawa K, Quirk MC, Chitwood RA, Watanabe M, Yeckel MF, Sun LD et al. Requirement for hippocampal CA3 NMDA receptors in associative memory recall. Science 2002; 297: 211-218.

75. Bleuler E. Dementia Praecox oder der Gruppe der Schizophrenien 1911420

76. Siegel A, Harrow M, Reilly FE, Tucker GJ. Loose associations and disordered speech patterns in chronic schizophrenia. J Nerv Ment Dis 1976; 162: 105-112.
77. Otmakhova NA, Lisman JE. Dopamine selectively inhibits the direct cortical pathway to the CA1 hippocampal region. J Neurosci 1999; 19: 1437-1445.

78. Schobel SA, Lewandowski NM, Corcoran CM, Moore H, Brown T, Malaspina D et al. Differential targeting of the CA1 subfield of the hippocampal formation by schizophrenia and related psychotic disorders. Arch Gen Psychiatry 2009; 66: 938-946.

Translational Psychiatry is an open-access journal published by Nature Publishing Group. This work is licensed under the Creative Commons Attribution-NonCommercial-No Derivative Works 3.0 Unported License. To view a copy of this license, visit http://creativecommons.org/licenses/by-nc-nd/3.0/

Supplementary Information accompanies the paper on the Translational Psychiatry website (http://www.nature.com/tp) 